\title{
Validity Study of the South Oaks Gambling Screen (SOGS) among distinct groups of Brazilian gamblers
}

\author{
Estudo de validade da escala South Oaks Gambling Screen junto a \\ grupos distintos de jogadores brasileiros
}

\author{
Maria Paula MT Oliveiraa, Maria Teresa Araujo Silva ${ }^{b}$ and Dartiu Xavier da Silveira ${ }^{c}$

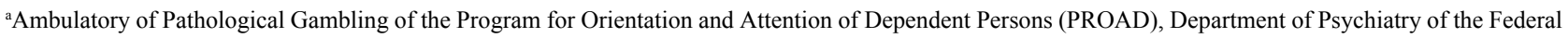 \\ University of São Paulo (UNIFESP). São Paulo, SP, Brazil. ' Department of Experimental Psychology, Institute of Psychology, University of São Paulo. São \\ Paulo, SP, Brazil. 'Coordinator of the Program for Orientation and Attention of Dependent Persons (PROAD), Department of Psychiatry of the Federal \\ University of São Paulo (UNIFESP). São Paulo, SP, Brazil
}

Abstract Objective: The main objective of this study was to assess the internal consistency and to perform a factor analysis of the Brazilian version of the SOGS - South Oaks Gambling Screen - scale, as well as its ability to discriminate between different profiles of gamblers.

Method: Two hundred and seventeen subjects were enrolled in the study: 46 gamblers under treatment at the Gamblers Treatment Unit of PROAD - Program for Orientation and Attention of Dependent Personsof the Federal University of São Paulo; 96 social gamblers and 75 subjects screened as pathological gamblers recruited at the local Jockey Club, video poker and bingo clubs.

Results: Differences in the score means of all three groups were statistically significant and were able to discriminate between social gamblers, pathological gamblers interviewed in a gambling site and the clinical sample. The internal consistency of the 20 -item scale measured by Cronbach's alpha was 0.9304 . Factor analysis resulted in a three-dimensional solution accounting for $58,6 \%$ of the total variance: a first factor composed mainly by questions related to the consequences of gambling; a second factor encompassing questions related to the gambling behavior of pathological gamblers; and a third and less expressive factor involving only two questions, probably a hybrid one of difficult interpretation.

Conclusions: The Brazilian version of the SOGS was a useful screen to discriminate Brazilian pathological gamblers from social gamblers as well as to differentiate clinical pathological from non-clinical pathological gamblers, and to identify different levels of severity.

Keywords Pathological gambling. Screening. Scales. Validity.

Resumo Objetivos: O objetivo desse estudo é avaliar a consistência interna e a dimensionalidade da versão da South Oaks Gambling Screen (SOGS) adaptada para uso em população brasileira e sua capacidade de discriminar diferentes tipos de jogadores.

Método: O estudo envolveu 217 jogadores - contatados no Jockey Clube de São Paulo, em casas de bingo e de vídeo pôquer -, sendo que 46 deles haviam procurado tratamento no Ambulatório de Jogo Patológico do Programa de Orientação e Atendimento a Dependentes da Universidade Federal de São Paulo.Entre eles 96 eram jogadores sociais e 75 eram classificados como prováveis jogadores patológicos.

Resultados: As diferenças das médias de pontuações das subamostras foram estatisticamente significantes, discriminando jogadores sociais e jogadores patológicos entrevistados em local de jogo e amostra clínica. A SOGS, em sua versão integral de 20 itens, apresentou consistência interna medida pelo modelo Alfa de Cronbach de 0,9304 . A análise fatorial da estrutura da escala resultou em uma solução de três dimensões, respondendo por $58,6 \%$ da variabilidade total dos dados na amostra: um primeiro fator constituído preponderantemente por questões referentes a conseqüências do comportamento de jogar; um segundo fator reunindo predominantemente questões relativas ao próprio comportamento de jogar dos jogadores patológicos; e um terceiro fator, menos decisivo no conjunto e composto de apenas duas questões, parecendo ser um fator híbrido de difícil interpretação.

Conclusões: A versão adaptada para o Brasil da SOGS mostrou-se um instrumento útil para discriminar

Sponsored by the CNPq (process $n^{\circ} 520591 / 96-8$ ).

Received on 28/11/2000. Reviewed on 5/2 and 9/5/2002. Approved on 16/7/2002. 
jogadores brasileiros patológicos de jogadores não-patológicos, como também diferenciou os grupos clínico e não-clínico de jogadores patológicos, identificando graus distintos de gravidade.

Descritores Jogo de azar. Peneiramento. Escalas. Validade.

\section{Introduction}

In the last twenty years, in several places around the world there has been an increasing offer of gambling, including statesponsored gambling, such as lotteries, bingo and casinos. The increase in the availability of gambling led some authors to consider pathological gambling as a problem of public health. ${ }^{1}$ There has also been an increase in the number of publications trying to warn the medical community about the importance of making an early diagnosis and of counseling the general population about the risks of pathological gambling. ${ }^{2-4}$

In 1980 pathological gambling was included as a category of impulsive disorder according to the DSM-III Diagnostic Criteria, ${ }^{5}$ being related to marriage, financial, emotional and legal problems among others. In the DSM-IV Diagnostic Criteria ${ }^{6}$ pathological gambling is characterized by the persistence and recurrence of the gambling behavior, indicated by the presence of at least five of the following items: (1) is preoccupied with gambling (e.g., preoccupied with reliving past gambling experiences, handicapping or planning the next venture, or thinking of ways to get money with which to gamble); (2) needs to gamble with increasing amounts of money in order to achieve the desired excitement; (3) has repeated unsuccessful efforts to control, cut back or stop gambling;(4) is restless or irritable when attempting to cut down, or stopping gambling; (5) gambles as a way of escaping from problems or of reliving a dysphoric mood (e.g., feelings of hopelessness, guilt, anxiety, depression); (6) after losing money gambling, often returns another day to get even ("chasing' one's losses); (7) lies to family members, therapist, or others to conceal the extent of involvement with gambling; (8) has committed illegal acts such forgery, fraud, theft or embezzlement to finance gambling; (9) has jeopardized or lost a significant relationship, job, or educational or career opportunity because of gambling; (10) relies on others to provide money to relieve a desperate financial situation caused by gambling.

In 1987 a screening instrument was developed to trace cases of pathological gambling. This scale, known as South Oaks Gambling Screen (SOGS), was developed based on the DSMIII criteria, demonstrating a high correlation with the diagnostic criteria of the DSM-III R $(\mathrm{r}=.94$, sd $=747, \mathrm{p}<.001){ }^{7}$ The SOGS was developed using a total of 1.616 subjects, including 867 patients hospitalized in the South Oaks Hospital due to drug abuse or pathological gambling, 213 members of the Anonymous Gamblers, 384 college students and 152 employees of the South Oaks hospital. A score of 5 or higher in the scale was considered as the most appropriate cutoff point to obtain a maximum reduction of both false positives and false negatives. The internal validity of the scale was confirmed through the assessment of its internal consistency using the Cronbach's alpha $(0.97, p<0.001)$ and the test-retest correlation $(0.71, \mathrm{df}=110, p<0.001){ }^{8}$

This scale has been used in therapeutical communities 9 and in other institutions to treat any dependence including pathological gambling. ${ }^{10,11}$ Besides being used in clinical populations, the SOGS is being used in epidemiological researches ${ }^{12-14}$ and has been translated into French ${ }^{15}$ and Spanish ${ }^{16}$ for the same purposes. Versions in German, Dutch, Italian, Swedish and other languages are also available. ${ }^{8}$ According to Shaffer ${ }^{17}$ it is the most used instrument to diagnose pathological gambling.

In a study in Turkey the scale was efficient to distinguish pathological gamblers from social ones. Out of 20 items of the scale, 16 were considered as appropriate. The authors attribute to cultural factors the fact that four of the items do not differentiate pathological from social gamblers. ${ }^{18}$

In Brazil the SOGS was translated into Portuguese and adapted to be used in our society in 1995 and has been used to differentiate pathological from non-pathological gamblers in a research with gamblers in gambling sites ${ }^{19}$ as well as in treating programs. ${ }^{20}$

This study assesses the internal validity and performance of the scale in distinct groups of Brazilian gamblers. Additionally we also examined the factorial structure of the scale in order to deepen the study about the content validity of the instrument.

\section{Method}

\section{Sample}

Subjects of this research were divided in three groups: a) a clinical sample composed by 46 gamblers who spontaneously sought treatment in the Ambulatory of Pathological Gambling of the Program for Orientation and Attention of Dependent Persons of the Federal University of São Paulo due to problems related to gambling behavior from March 1998 to July 2000; b) a non-clinical sample, composed by 96 non-pathological gamblers according to the SOGS, hereinafter called 'social gamblers', who were studied in gambling sites; and c) a non-clinical sample of pathological gamblers composed by 75 gamblers classified as probable pathological gamblers, also identified in gambling sites. Subjects conforming non-clinical groups were recruited among frequenters of three types of gam- 
bling sites: bingo, video-poker and Jockey Club. Twenty-five questionnaires of probable pathological gamblers for each gamble category were collected. ${ }^{19}$

\section{Instrument}

We used the SOGS - South Oaks Gambling Screen, ${ }^{7}$ translated into Portuguese and adapted as described bellow. It included questions about socio-demographic data, gambling in the prior 12 months, frequency of gambling in the last 30 days for each type of gamble and questions about the last 12 months for other items of the scale. A question about alcohol consumption by the gamblers' parents was added. However, the answers to this complementary question were not included in the calculation of the total score, thus assuring its comparability with other versions of the instrument. The original scale has 20 questions to assess gamblers' behaviors that were kept in the questionnaire. The cutoff point used was 5 , being considered as probable pathological gamblers those who had a score equal to or higher than 5 . The other questions added to the scale were not computed in this score.

\section{Adaptation of the instrument}

A back translation of the scale was performed in order to assure a reliable translation of the scale into Portuguese. The translated version was administered to 10 patients who sought the PROAD due to problems connected to gambling. The questionnaire has been refined at each application, to facilitate its understanding and to improve the quality of the answers. Blank answers, contradictory ones and explicit doubts were taken into account in this review. The last application, from which was originated the adapted final version, was performed with 20 gamblers, being 10 in the Jockey Club and 10 in a bingo club. In this version, the questionnaire is self-applicable, that is, the subject fills in the questionnaire by him/herself, after being properly instructed. The final version of this scale is available under request.

\section{Procedure}

A non-blind trained psychologist applied the questionnaire to gamblers who sought attention in the Gamblers Treatment Unit of the PROAD - Federal University of São Paulo during the first interview. In the field, the application was carried out by four trained researchers who went in pairs to the three types of gambling sites and asked the gambler's collaboration, explained the aims of the study and that they should answer the questionnaires by themselves. The questionnaires were filled in individually, preferentially near to the researchers and then were put into an envelope, thus assuring anonymity. Three hundred and forty-one gamblers were invited to answer from which 139 refused, 21 returned blank questionnaires and 10 of them were invalidated due to contradictory answers. The detailed description of the field application was published elsewhere. ${ }^{19}$

\section{Statistical analysis}

The results were analyzed using parametric and non-para- metric statistic tests, with the SPSS and EPIINFO programs.

In order to verify if in a sample two or more variables were independent from each other we used the chi-square test. When data were presented as frequencies of categories, we also used the chi-square test to determine the significance of differences between two independent groups. When the studied variable had a normal distribution in the population from which the samples were extracted, we used the Student's t test to compare two independent means. When the studied continuous variable had not a normal distribution, non-parametric tests were used to compare the independent samples (Kruskal-Wallis). In order to examine the interrelations between three or more variables we used the logistic regression model as the dependent variable was dichotomic. Significance levels of 0.05 were adopted and the respective degrees of freedom (df) were presented.

The Principal Components Analysis (PCA) of the SOGS enables the detection of the number of components (factors of the scale), of the total variance explained of each component and of the factor loadings of each question of the scale. The number of components provides the quantity of dimensions of the scale that are independent between them. The total variance explained gives the measure of the capacity of each component to represent the total variability of the data of our sample. The factor loading is the measure of the intensity of the relationship of one variable (question of the scale) with one component.

In order to examine the structure of the SOGS used in this study we used the Principal Components Analysis of the correlation matrix of the questions which compose the scale. In order to determine the number of components of the scale we used as a criterion the inclusion of the components corresponding to the eigenvalues of the matrix that were greater than one. After obtaining factor loadings, we used the varimax rotation method which supplied a new rotated factor loadings, making easier the interpretation of the factors. In order to identify which questions more represented by which component we used as a criterion with a factor loading greater than 0.4 .

For the inclusion of a question in the model to be submitted to the Principal Component Analysis (PCA) we used as a criterion the coefficient of determination $\left(\mathrm{R}^{2}\right)$ greater than 0.15 .

In the factor analysis of the instrument correlation matrices were built to verify the $2 \times 2$ correlation of the questions. We also calculated the coefficient of determination $\left(\mathrm{R}^{2}\right)$ of each question in relation to all the others in order to determine occasional questions with low relevance in the whole. From this procedure we built integral matrices which comprised all questions of the scale. The analysis of the principal components (PCA) was then applied to the matrices of correlation. The factors composing the instrument were determined selecting those with an total variance explained greater than $1(\mathrm{EV}>1)$. We used the orthogonal rotation through the varimax method to obtain the rotated factor loadings. 


\section{Results}

\section{Sample description}

The studied sample was composed by 217 male (82\%) and 38 female subjects (18\%). The age distribution varied from 16 to 76 years and the mean age was 40.3 years with a standard deviation of 11.6. Regarding the marital status, 52 subjects were single $(24 \%), 129$ were married $(60 \%)$ and 31 were divorced (14\%). As for the religious belief, there were 145 Catholics (68\%), 11 Protestants (5\%), 19 Spiritualists (9\%) and 26 claimed having no religion (12\%). The majority $(91 \%)$ of studied gamblers was working: hundred and fifty-three subjects (71\%) reported working full time, 25 part-time (12\%) and 17 did it occasionally $(8 \%)$. Among those who informed about their monthly household income, the mean was US\$ 2,492.50 $( \pm 2,401.50)$ and the median was US\$ $1,750.00$, ranging from zero to US\$ $10,000.00$. However, almost $28.1 \%$ of the sample (61 subjects) did not inform their monthly household income. Regarding schooling, $40.7 \%$ of the gamblers reported having finished college and the same percentage reported having finished high school; $11.2 \%$ had studied up to the $8^{\text {th }}$ grade and only $7.5 \%$ did not reach it.

Comparing the three groups regarding these variables, the only significant differences were those related to job and income. In the clinical population we found more unemployed gamblers (clinical, 17.8\%; pathological non-clinical, 2.7\%; social gamblers, $3.1 \%, \mathrm{x} 2=18.4 ; \mathrm{df}=6 ; \mathrm{p}<0.01)$ and the income of the pathological group was higher than that of the others (the median of the clinical population was US\$ 1,500.00, that of the pathological non-clinical was US\$2,500.00, and of the social gamblers was US\$1,750.00, KW $p=0.014$ ).

\section{Assessment of the performance of the SOGS}

SOGS scores in the studied population ranged from 0 to 20 , with a mean of 7.17, standard deviation of 5.95 and median of
6.0. Among social gamblers studied in gambling sites, SOGS scores ranged from 0 to 13 points, with a mean of 1.95 points, standard deviation of 2.27 and median of 1.0. Among gamblers classified as probable cases of pathological gamblers who were interviewed in gambling sites, SOGS scores ranged from 4 to 22 points, the mean being 9.43 points, the standard deviation, 4.17 , and the mean, 8.0. SOGS scores in the clinical subsample ranged from 5 to 20 points, with a mean of 14.37 , standard deviation of 3.06 and median of 14 . The differences between the means in the three sub-samples were statistically significant (Kruskal Wallis: $\mathrm{x}^{2}=153.37$; $\mathrm{df}=2 ; \mathrm{p}<0.001$ ), as shown in Figure.

The affirmative answers of each group for each item of the SOGS scale are shown in Table 1.

Considering that the scale differentiates pathological from social gamblers, we analyzed the affirmative answers to the items of the scale excluding the group of social gamblers, aiming to detect the ability of the scale to differentiate clinical

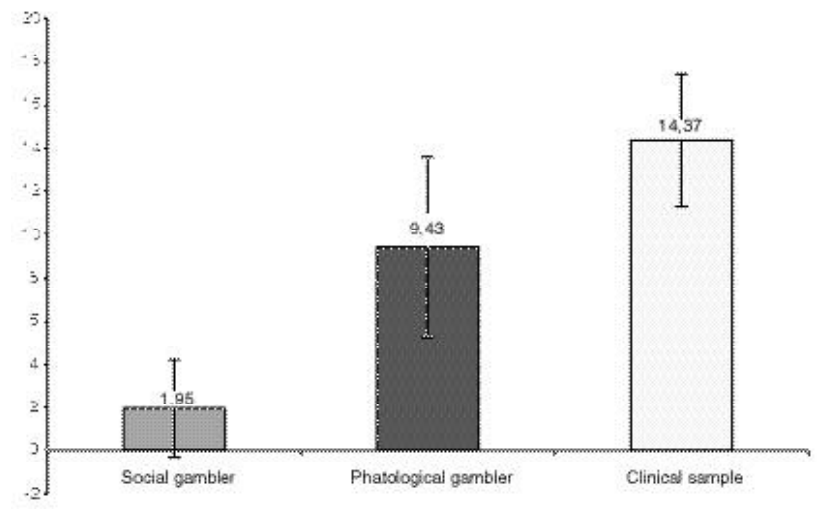

Figure - Mean score in the SOGS of social and pathological gamblers and clinical sample (Kruskal Wallis: $x^{2}=153.37$; $d=2 ; p<0.001$ ).

Table 1 - Affirmative answers to the questions of the SOGS by social gamblers, population of non-clinical pathological gamblers and clinical population of gamblers.

\begin{tabular}{|c|c|c|c|c|c|c|}
\hline \multirow[t]{2}{*}{ Question } & \multicolumn{2}{|c|}{ Social Gamb. } & \multicolumn{2}{|c|}{ Pathological Gamb. } & \multicolumn{2}{|c|}{ Clinical } \\
\hline & $\mathrm{N}$ & $\%$ & $\mathrm{~N}$ & $\%$ & $\mathrm{~N}$ & $\%$ \\
\hline 1. Came back to recover what he/she has lost & 10 & 11.5 & 27 & 37.5 & 34 & 73.9 \\
\hline 2. Claimed winning when losing & 17 & 18.7 & 27 & 38.6 & 18 & 40.0 \\
\hline 3. Feels as already had gambling problems & 9 & 9.7 & 53 & 71.6 & 40 & 87.0 \\
\hline 4. Gambled more than had planned & 24 & 25.8 & 62 & 87.3 & 42 & 91.3 \\
\hline 5. Is criticized for gambling & 36 & 37.9 & 67 & 93.1 & 42 & 91.3 \\
\hline 6. Felt guilty for gambling & 12 & 13.3 & 57 & 82.6 & 41 & 89.1 \\
\hline 7. Would like to stop gambling & 6 & 6.3 & 39 & 56.5 & 33 & 33.3 \\
\hline 8. Concealed gambling signals & 5 & 5.3 & 39 & 52.7 & 36 & 78.3 \\
\hline 9. Argued due to gambling habit & 6 & 10.2 & 39 & 72.2 & 37 & 82.2 \\
\hline 10. Borrowed money and did not pay it & 0 & 0 & 24 & 33.3 & 22 & 47.8 \\
\hline 11. Lost working time & 11 & 12.0 & 43 & 59.7 & 31 & 67.4 \\
\hline 12. Used money of the household expenses & 2 & 2.9 & 27 & 43.5 & 37 & 82.2 \\
\hline 13. Used the money of him/her wife/husband & 1 & 1.6 & 15 & 27.3 & 27 & 58.7 \\
\hline 14. Used money of other relatives & 2 & 3.2 & 17 & 31.5 & 24 & 52.2 \\
\hline 15. Used money from banks, loan or credit companies & 4 & 6.3 & 15 & 28.8 & 30 & 65.2 \\
\hline 16. Used credit cards & 2 & 3.2 & 15 & 27.8 & 23 & 50.0 \\
\hline 17. Used money from usurers & 2 & 3.2 & 13 & 24.1 & 20 & 43.5 \\
\hline 19. Sold personal or family real estates & 1 & 1.6 & 11 & 21.2 & 27 & 58.7 \\
\hline 20. Issued bounced checks & 3 & 4.8 & 22 & 39.3 & 34 & 73.9 \\
\hline
\end{tabular}


from non-clinical populations of pathological gamblers. Therefore, comparing the group composed by the clinical population with the group of pathological gamblers studied in gambling sites, we observed significant differences in 11 out of 20 questions of the scale: question $1,\left(\mathrm{x}^{2}=14.90, \mathrm{df}=1, p<0.001\right)$; question $3\left(\mathrm{x}^{2}=3.82, \mathrm{df}=1, p<0.05\right)$; question $8\left(\mathrm{x}^{2}=7.90, \mathrm{df}=1\right.$, $p<0.05)$; question $12\left(\mathrm{x}^{2}=16.22, \mathrm{df}=1, \mathrm{df}=1, p<0.001\right)$; question $13\left(\mathrm{x}^{2}=10.18, \mathrm{df}=1, p<0.001\right)$; question $14\left(\mathrm{x}^{2}=4.39, \mathrm{df}=1\right.$, $p<0.05)$; question $15\left(\mathrm{x}^{2}=13.00, \mathrm{df}=1, p<0.001\right)$; question 16 $\left(\mathrm{x}^{2}=5.20, \mathrm{df}=1, p<0.05\right)$; question $17\left(\mathrm{x}^{2}=4.23, \mathrm{df}=1, p<0.05\right)$; question $19\left(\mathrm{x}^{2}=14.49, \mathrm{df}=1, p<0.001\right)$; question $20\left(\mathrm{x}^{2}=12.23\right.$, $\mathrm{df}=1, p<0.001)$. In all cases there were more affirmative answers in the clinical group.

For questions investigating if gamblers' parents gambled or drank too much, there were no significant differences between the three groups. However, the ratio of gamblers in the clinical population that reported that their parents drink or drank too much was higher than the other groups (clinical population $=26.6 \%$, pathological gamblers $=16.6 \%$, social gamblers $\left.=8.7 \%, \mathrm{x}^{2}=9.94, \mathrm{df}=2, p<0.05\right)$.

\section{Factor analysis and internal consistency of the SOGS scale}

Observing data related to the correlations and multiple correlations of the answers of the SOGS scale we noticed that all questions were related with the others being, therefore, important variables in the whole.

The SOGS scale in its 20-item integral version had internal consistency as measured by the Cronbach's alpha model of 0.9304 .

The results of the Principal Components Analysis with the subsequent orthogonal rotation of the matrix of factor loadings are in Table 2. This matrix was arranged in a way that the columns are in decreasing order of the variance explained by the factors. Furthermore, in each factor the questions with factor

Table 2 - Factors originated from the Main Component Analysis of the reduced matrix.

\begin{tabular}{|c|c|c|}
\hline Factor 1 & $\mathrm{AEV}=45.0 \%$ & Loadings \\
\hline 04. Gamb & & 0.8341 \\
\hline 12. Used & nses & 0.83276 \\
\hline 17. Borrov & & 0.82983 \\
\hline 13. Used & sband & 0.67427 \\
\hline 15. Borrov & n/credit companies & 0.67426 \\
\hline 18. Sold s & lal papers & 0.65276 \\
\hline 20. Issu & & 64429 \\
\hline 16. Borrov & & 5277 \\
\hline \multicolumn{3}{|c|}{ Factor $2 \quad \mathrm{AEV}=52.6 \%$} \\
\hline \multirow{2}{*}{\multicolumn{2}{|c|}{$\begin{array}{l}07 \text {. Would like to stop gambling but thought he/she was not able to } \\
02 \text {. Claimed winning when loosing }\end{array}$}} & 0.74749 \\
\hline & & 0.72210 \\
\hline \multirow{2}{*}{\multicolumn{2}{|c|}{$\begin{array}{l}\text { 14. Borrowed money from other relatives } \\
08 \text { Concealed gambling papers or other gambling signals }\end{array}$}} & 0.66325 \\
\hline & & 0.65273 \\
\hline \multicolumn{2}{|c|}{ 03. Feels as sometimes having gambling problems } & 0.64575 \\
\hline & 0.63569 \\
\hline \multicolumn{2}{|c|}{ 05. People have already criticized the fact you gamble } & 0.62233 \\
\hline \multicolumn{2}{|c|}{ 10. Borrowed money and did not pay it back due to gambling } & 0.59063 \\
\hline \multicolumn{2}{|c|}{ 19. Sold personal or family real estates } & 0.54900 \\
\hline \multicolumn{2}{|c|}{ 09. Argument about money centered in gambling } & 0.50345 \\
\hline \multicolumn{3}{|c|}{ Factor $3 \quad \mathrm{AEV}=58.6 \%$} \\
\hline \multirow{2}{*}{\multicolumn{2}{|c|}{$\begin{array}{l}\text { 11. Lost working (or school) time due to gambling } \\
01 \text {. Comes back another day to get even ('chasing' one's losses) }\end{array}$}} & 0.65787 \\
\hline & & 0.63260 \\
\hline
\end{tabular}

loading higher than 0.5 are displayed first and factor loadings lower than 0.4 were replaced by zero.

From the factor analysis we obtained three factors with total variance explained of $58.6 \%$. The composition of the three factors obtained by the Principal Components Analysis as well as the factor loadings of each question of the SOGS scale obtained from the orthogonal rotation of the reduced matrix of the scale are in Table 2.

\section{Discussion}

The results obtained through the SOGS enabled us to distinguish two groups of gamblers in the gambling sites: social and pathological. Besides, the scores obtained from the scale applied in gamblers who sought treatment were higher than scores of pathological gamblers identified in gambling sites (non-clinical population of pathological gamblers). These data may reflect a higher degree of severity of gamblers seeking treatment. However, we have to highlight the possibility that this different punctuation could, at least partially, stem from a bias of the answers to the scale's questions, i.e., gamblers seeking treatment would tend to answer the questions as to stress the severity of their condition, whereas gamblers interviewed in gambling sites would tend to minimize the severity of their condition. The different methodologies in the application of the questionnaires may have contributed to accentuate this dissimilarity, as the clinical population was directly interviewed whereas the non-clinical population answered the questionnaire in a selfreported way.

In this study, the fact that we found a greater rate of unemployed people among the clinical population of gamblers probably reflects a higher degree of involvement of these subjects with the gambling behavior. Alternatively, although less probably, we may suppose that the condition of being unemployed could either intensify the gambling behavior or lead these gamblers to seek more treatment.

Regarding the performance of the scale, not only it was able to discriminate between pathological and non-pathological gamblers but also to differentiate clinical from non-clinical pathological gamblers, identifying distinct degrees of severity. Additionally, we have identified eleven items in the scale with this discriminating capability. This group of eleven questions might represent a sub-scale to predict the need of a therapeutical intervention.

The three groups of gamblers are undistinguishable as for having parents who gamble or gambled too much in the past. However, among gamblers being treated we noticed a greater ratio of parents with problems related to the excessive consumption of alcohol. It is possible that the parents' alcohol abuse or dependence conforms a path of dependence that was 'taught' to their children. We could also consider that both chemical dependence and pathological gambling are different clinical expressions of a same psychopathological dimension in the continuum of disorders concerning the control of impulses. Pathological gambling has been considered a type of dependence $^{21}$ and studies suggest that there is a common genetic 
vulnerability between pathological gambling and alcohol dependence among men. ${ }^{22}$

In diagnostic procedures that rely on the information supplied by patients physicians have to tackle with the problem of its reliability. In order to optimize the reliability of the information, researchers assess the several symptoms related to different aspects of a same pathological condition. Therefore, a scale of symptoms tends to be more reliable than the items that compose it if they are positively correlated. In our study, the internal consistency of the SOGS as measured by the Cronbach's Alpha was 0.93, indicating that the questions converged to the same construct. Studies using the SOGS in other countries ${ }^{18}$ suggest that several of the questions of the scale may lose their discriminating capability due to transcultural differences. This phenomenon was not observed in our society. As none of the questions had a low correlation with the others, we may conclude that the integral version of the scale is the one that accounts for the best performance of the instrument in our environment.

In our study the factor analysis of the scale's structure resulted in a three-dimensional solution. From the three evidenced factors, one was mainly composed by questions related to the consequences of the gambling behavior, whereas a second factor was related mainly to the proper behavior of gambling in pathological gamblers. Transitorily we may name the latter as Diagnostic, whereas the former could be called Adverse consequences or Complications. A third factor, the least decisive one and composed only by two questions, seems to be a hybrid one, difficult to be interpreted. It must be highlighted that screening scales measure psychopathological dimensions not necessarily specific to a certain psychiatric disorder. Therefore, from the clinical point of view, certain dimensions may not be clear enough to specify the psychopathological entity they are referred to. This may be a possible explanation to obtain this third factor. Other studies involving different populations of gamblers would be needed to verify if this kind of grouping of questions is repeated, confirming our finding of the stability of the factor structure. Moreover, studies comparing the discriminating capability of the SOGS with that of other instruments would be desirable.

\section{Conclusion}

The SOGS not only was able to discriminate between pathological and non-pathological gamblers but also to differentiate the group of clinical from the non-clinical pathological gamblers, identifying different levels of severity. Complementarily, we identified eleven items in the scale that have this discriminating capability. This group of eleven questions could occasionally represent a sub-scale to predict the need of a therapeutical intervention.

\section{References}

1. Volberg RA. The prevalence and demographics of pathological gamblers: implications for public health. Am J Public Health 1994;84:237-41.

2. Miller MM. Medical approaches to gambling issues II: the medical response. Wisconsin Med J 1996;95:635-42.

3. Kramer D. "Ask the gambling question," FPs told as "secret" addiction becomes more common. C maj 1997;157:61-2.

4. Pasternak AVT. Pathological gambling: America's newest addiction? Am Family Physician 1997;56:1293-6.

5. American Psychiatric Association. Diagnostic and statistical manual of mental disorders. Washington (DC): American Psychiatric Association; 1980.

6. American Psychiatric Association. Diagnostic and statistical manual of mental disorders. Washington (DC): American Psychiatric Association; 1994.

7. Lesieur HR, Blume SB. The south oaks gambling screen (SOGS): a new instrument for the identification of pathological gamblers. Am J Psychiatry 1987; $144: 1184-8$

8. Lesieur HR, Blume SB. Revising the south oaks gambling screen in different settings. J Gambling Studies 1993;9:213-23.

9. Lesieur HR, Heineman M. Pathological gambling among youthful multiple substance abusers in a therapeutic community. Br J Addic 1988;83:765-71.

10. Blume SB. Treatment for the addictions in a psychiatric setting. Br J Addic 1989;84:727-9.
11. Lesieur HR, Blume SB. Evaluation of patients treated for pathological gambling in a combined alcohol, substance abuse and pathological gambling treatment unit using the Addiction Severity Index. Br J Addic 1991;86:1017-28.

12. Volberg RA, Steadman HJ. Refining prevalence estimates of pathological gambling. Am J Psychiatry 1988;145:502-5.

13. Abbott MW, Volberg RA. The New Zealand National Survey of problem and pathological gambling. J Gambling Studies 1996;12:143-60.

14. Wallish L, editor. Gambling in Texas: 1992 a survey of adult gambling behavior. Austin: Texas Commission on Alcohol and Drug Abuse; 1993.

15. Ladouceur R. Prevalence estimates of pathological gambling in Quebec. Can J Psychiatry 1991;36:732-4.

16. Martinez-Pina A, Guirao de Parga JL, Fuste i Vallverdu R et al. The Catalonia survey: personality and intelligence structure in a sample of compulsive gamblers. J Gambling Studies 1991;7:275-99.

17. Shaffer HJ, Hall HM, Vander BJ. Estimating the prevalence of disordered gambling behavior in the United States and Canada: a research synthesis. Am J Public Health 1999;89:1369-76.

18. Duvarci I, Varan A, Coskunol H, Ersoy MA. DSM-IV and the south oaks gambling screen: diagnosing and assessing pathological gambling in Turkey. J Gambling Studies 1997;13:193-206.

19. Oliveira MPMT, Silva MTA. Pathological and non-pathological gamblers: a survey in gambling settings. Substance Use Misuse 2000;35:1573-83. 
20. Oliveira MPMT, Silva ACP, Silveira DX. Um programa assistencial para o transtorno de jogo patológico. Bol Psiquiatr 1999;32:25.

21. Shaffer HJ. The most important unresolved issue in the addictions: conceptual chaos. Substance Use Misuse 1997;32:1573-80.

22. Slutske WS, True WR, Goldberg J, Xian SEH, Lyons MJ, Tsuang M. Common genetic vulnerability for pathological gambling and alcohol dependence in men. Arch Gen Psychiatry 2000;57:666-73
Correspondence:

Maria Paula M. T. Oliveira

Proad, Escola Paulista de Medicina, Unifesp

Rua dos Otonis, 887

04025-002 São Paulo, SP, Brazil

E-mail: mpm_fto@uol.com.br 